\title{
Effect of Magnetic Wedge Characteristics on Torque Ripple and Loss in Interior Permanent Magnet Synchronous Motor
}

\author{
Manabu Horiuchi ${ }^{* a}$ ) \\ Yinggang $\mathrm{Bu}^{*}$ \\ Mitsuhide Sato*
}

\author{
Member, \\ Member, \\ Member,
}

\author{
Ryoken Masuda* \\ Masami Nirei** \\ Tsutomu Mizuno*
}

\author{
Student Member \\ Senior Member \\ Fellow
}

(Manuscript received Jan. 00, 20XX, revised May 00, 20XX)

\begin{abstract}
An interior permanent magnet synchronous motor (IPMSM) is characterized by high efficiency in a wide range of applications. However, when operating at high speeds, torque ripple and rotor loss occur because of the spatial harmonics generated by fluctuations in the airgap permeance. This study demonstrates the suppression of torque ripple and harmonic loss by magnetic wedges using finite element analysis (FEA). First, the authors examined the torque and loss characteristics by varying the slot opening width and relative permeability of the magnetic wedge. Results indicate that the torque ripple can be suppressed even if the opening width is widened to half the slot pitch. However, this improvement effect saturates when the relative permeability of the magnetic wedge becomes larger than $\mu_{\mathrm{r}}=10$. Furthermore, the authors confirmed the effect of the magnetic wedge by visualizing the harmonic components of the eddy current loss. The findings reveal that the eddy current loss represents a trade-off between the stator and rotor when using the magnetic wedge.
\end{abstract}

Keywords: IPMSM, harmonic loss, torque ripple, magnetic wedge, magnetic composite material

\section{Introduction}

An interior permanent magnet synchronous motor (IPMSM) can be driven with high efficiency in a wide range of operations, from low-speed and large-torque driving to high-speed driving. For this reason, it has attracted research attention from many fields for applications, including automobile main motor and processing machine spindle axis. Notably, there have recently been reports of cases of downsizing by driving the motor at a high speed ${ }^{(1)}$.

However, the magnetic flux density at the IPMSM airgap has many spatial harmonic components, and the torque ripple is generated ${ }^{(2)}$. Several methods have been proposed for torque ripple reduction. Reference (3) proposes to add compensation to the torque command using the torque-estimation formula to suppress torque ripple. Moreover, reference (4) proposes to superimpose harmonic components on the current to cancel the torque ripple. Finally, references (2) and (5) propose the stator and rotor shape design for reducing torque ripple. However, few reports exist on suppressing the torque ripple of IPMSM in wide operating areas.

Furthermore, harmonic loss at high-speed drive are generated by the spatial harmonic component of the magnetic flux density ${ }^{(6)}$. Reference (7) proposes a soft magnetic material and its application examples for reducing iron loss in the stator. Moreover, reference (6) proposes providing slits on the outer circumference of the rotor core for reducing iron loss in the rotor. However, as shown in reference (2), the rotor must have enough strength for the

a) Correspondence to: Manabu Horiuchi. E-mail: 19hs207a@shinshu-u.ac.jp

* Faculty of Engineering, Shinshu University 4-17-1, Wakasato, Nagano 380-8553, Japan

** National Institute of Technology, Nagano College 716, Tokuma, Nagano 381-8550, Japan centrifugal force. There is a concern that the strength may be decreased by changing the shape such as providing a slit. Thus, there is a trade-off between rotor core strength and iron loss. However, there are no reports of reduced torque ripple and loss without reducing rotor strength. Magnets temperature are raised by rotor loss. Nd-based magnets are required with a high coercive force containing many heavy rare earth metals. Reducing rotor loss is an important issue from the perspective of resource saving.

The authors had clarified that inserting magnetic wedges made of a magnetic composite material in slot opening can suppress torque ripple and harmonic loss ${ }^{(8)(9)}$. There are various reports focused on motor performance improvement using magnetic wedges. References (10)-(12) proposes Carter's coefficient with variable size of the magnetic wedge. The average magnetic flux density of the airgap depending on the slot opening width can be calculated using Carter's coefficient. However, the effects of the size and relative permeability of the magnetic wedge on the harmonic components of the magnetic flux density has not been clarified. Moreover, references (13) and (14) proposes the effect of loss reduction using magnetic wedges. The effect of the magnetic wedge is clarified in terms of loss separation and temperature evaluation. However, the loss-suppression mechanism due to the magnetic wedge and local harmonic loss generation has not been clarified.

Therefore, this study demonstrates the suppression mechanism of torque ripple and harmonic loss by magnetic wedges using FEA. The torque and loss characteristic relationship is clarified by varying the slot opening width and relative permeability of the magnetic wedge. Furthermore, the authors confirm the effect of the magnetic wedge by visualizing the harmonic components of the eddy current loss. This paper describes the following contents: (1) Relationship between harmonic components in the magnetic flux density of the airgap and magnetic wedges. 
(2) Effect of the magnetic wedge size and relative permeability on torque ripple and loss.

(3) Identification of the harmonic loss location and the guidelines for magnetic wedge design.

\section{The Basic Structure of IPMSM and Material Properties of Magnetic Wedge}

2.1 Structure and Specifications of IPMSM Fig. 1(a) shows the basic structure of the IPMSM. This motor is used in a processing machine spindle axis. The distributed winding is an armature winding with three slots in each pole and each phase.

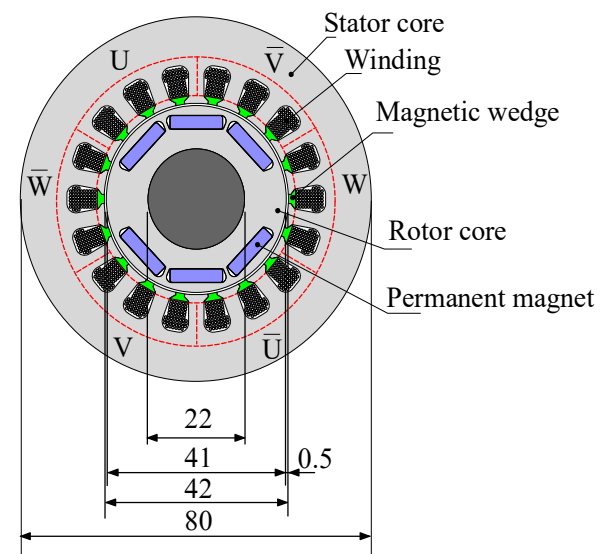

(a) Cross-sectional view

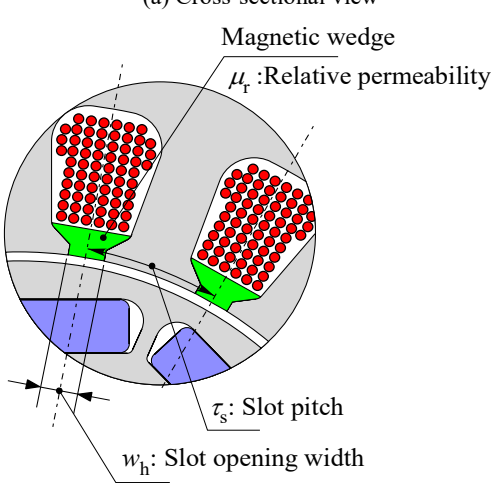

(b) Enlarged view of the stator slot

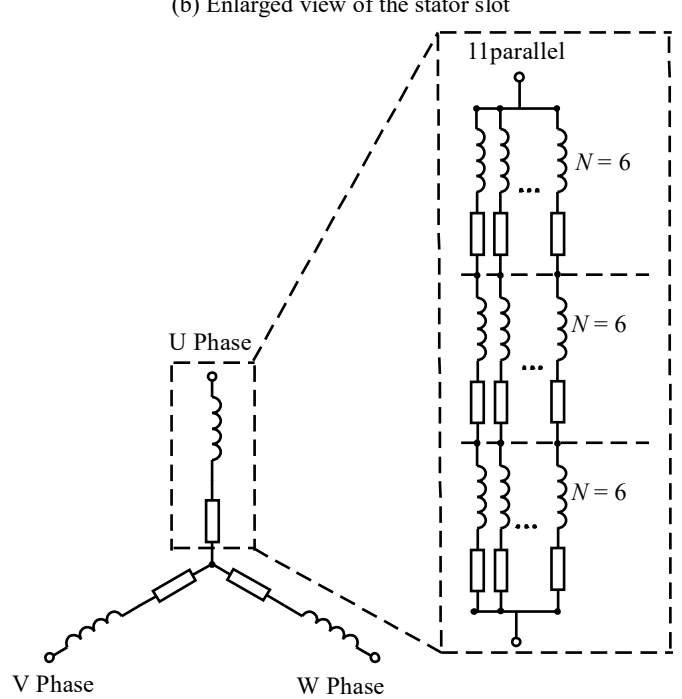

(c) The coil winding diagram

Fig. 1. Basic configuration of IPMSM (Unit: mm).
Table 1. Specifications of IPM motor.

\begin{tabular}{|c|c|c|c|c|}
\hline & Item & Symbol & Value & (unit) \\
\hline \multirow[t]{5}{*}{ Motor } & Rated output power & $P_{\mathrm{r}}$ & 2155 & (W) \\
\hline & Rated torque & $T_{\mathrm{r}}$ & 2.06 & $(\mathrm{Nm})$ \\
\hline & Rated rotational speed & $N_{\mathrm{r}}$ & 10,000 & $\left(\min ^{-1}\right)$ \\
\hline & $\begin{array}{l}\text { Maximum rotational } \\
\text { speed }\end{array}$ & $N_{\mathrm{m}}$ & 30,000 & $\left(\min ^{-1}\right)$ \\
\hline & Stack thickness & $l$ & 87 & $(\mathrm{~mm})$ \\
\hline \multirow[t]{2}{*}{ Rotor } & Number of poles & $2 p$ & 2 & \\
\hline & Diameter of rotor & $D_{\mathrm{r}}$ & 41 & $(\mathrm{~mm})$ \\
\hline \multirow[t]{6}{*}{ Stator } & Diameter of stator & $D_{\mathrm{s}}$ & 80 & $(\mathrm{~mm})$ \\
\hline & Length of gap & $l_{\mathrm{g}}$ & 0.5 & $(\mathrm{~mm})$ \\
\hline & Number of slots & $N_{\mathrm{s}}$ & 18 & \\
\hline & Number of turns & $N$ & 6 & \\
\hline & Number of parallel & & 11 & \\
\hline & Diameter of conductor & $D_{\underline{\underline{\mathrm{w}}}}$ & 0.55 & $(\mathrm{~mm})$ \\
\hline \multirow{2}{*}{$\begin{array}{l}\text { PWM } \\
\text { Drive }\end{array}$} & Carrier frequency & $f_{\mathrm{c}}$ & 12.5 & $(\mathrm{kHz})$ \\
\hline & $\begin{array}{l}\text { Inverter DC input } \\
\text { voltage }\end{array}$ & $V_{\text {in }}$ & 280 & (V) \\
\hline
\end{tabular}

It is two-poled because it is used under high-speed rotation. The rotor used six Nd-Fe-B sintered magnets, and three pairs constitute one pole. Fig. 1(b) shows an enlarged view of the stator slot section in the cross-sectional view of Fig. 1(a). The winding slot has a $w_{\mathrm{h}}=2 \mathrm{~mm}$ wide opening for distributed winding insertion, into which a magnetic wedge is inserted. Fig. 1(c) shows the coil winding diagram. The coil comprises 11 magnet wire conductors connected in parallel. The number of turns is 6 , and three coils are connected in series per phase.

Table 1 shows the specifications of the IPMSM. The rated rotation speed is $10,000 \mathrm{~min}^{-1}$, and the maximum rotation speed is $30,000 \mathrm{~min}^{-1}$. The inverter DC input voltage is $280 \mathrm{~V}$, and the carrier frequency is $12.5 \mathrm{kHz}$. Previous reports revealed that the magnetic wedge has a significant effect on high-speed rotation drive ${ }^{(8)}$. Thus, in this study, we focused on the characteristics at $30,000 \mathrm{~min}^{-1}$.

Table 2 shows the analysis conditions. The analysis method is a two-dimensional transient-response magnetic field where the stator and rotor core are made from magnetic steel sheets. In addition, the permanent magnet is an Nd-Fe-B sintered magnet, and the magnetic wedge is made from a magnetic composite material.

2.2 Material Properties of Magnetic Wedge Fig. 2 shows the magnetic properties of the magnetic composite material. The magnetic composite material is produced by mixing an Fe-based amorphous powder (with an average particle size of 2.6 $\mu \mathrm{m})$ with a polymer resin, and then heat curing ${ }^{(13)}$. The magnetic

\begin{tabular}{|c|c|c|}
\hline \multicolumn{2}{|c|}{ Item } & Contents \\
\hline \multicolumn{2}{|l|}{ Software } & JMAG-Designer (x64) Ver. 19.1 \\
\hline \multicolumn{2}{|c|}{ Analysis method } & $\begin{array}{l}\text { Two-dimensional transient response magnetic field } \\
\text { analysis }\end{array}$ \\
\hline \multicolumn{2}{|l|}{ Solution } & FEM \\
\hline \multicolumn{2}{|c|}{ Mesh size } & $\begin{array}{l}\text { 1) Winding: } 0.1 \mathrm{~mm} \\
\text { 2) Wedge: } 0.3 \mathrm{~mm} \\
\text { 3) Slot space: } 0.2 \mathrm{~mm} \\
\text { 4) Rotor core: } 0.2 \mathrm{~mm} \\
\text { 5) Permanent magnet and stator core: } 0.5 \mathrm{~mm}\end{array}$ \\
\hline \multicolumn{2}{|c|}{ Analysis area } & Analysis in 1.2 times the analysis model \\
\hline \multirow[t]{3}{*}{ Material } & Stator & $\begin{array}{l}\text { 1) Copper: Electric resistivity } \rho=1.72 \times 10^{-7}(\Omega \mathrm{m}) \\
\text { 2) Core: Nippon Steel Corporation, } 35 \mathrm{H} 210 \\
\text { 3) Magnetic wedge: Magnetic composite material } \\
\text { Magnetic powder: Fe-based Amorphous } \\
\text { Average particle size: } 2.6 \mu \mathrm{m} \\
\text { Volume ratio of magnetic powder: } 64 \text { vol. } \%\end{array}$ \\
\hline & Rotor & $\begin{array}{l}\text { 1) Permanent magnet: Hitachi Metals, NMX-34EH } \\
\text { 2) Core: Nippon Steel Corporation, 50H470 } \\
\text { 3) Shaft: Carbon steel, S45C }\end{array}$ \\
\hline & Other & Air: $\rho=\infty \Omega \mathrm{m}, \mu_{\mathrm{r}}=1$ \\
\hline
\end{tabular}




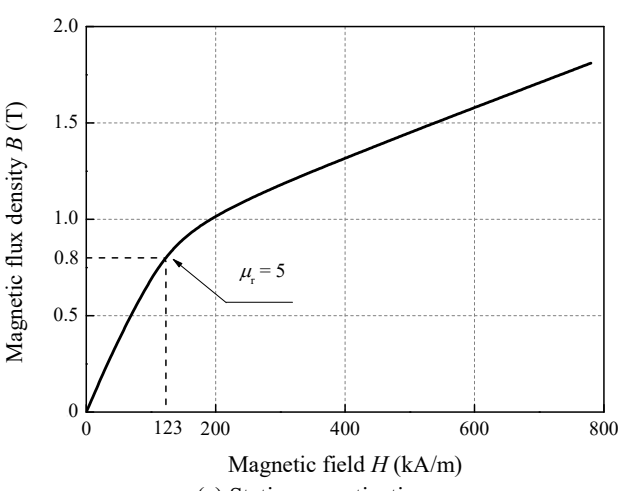

(a) Static magnetization

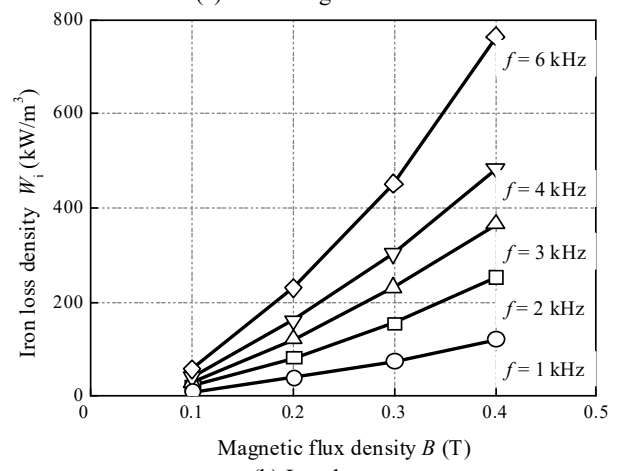

(b) Iron loss

Fig. 2. Magnetic characteristics of magnetic composite material.

composite material, unlike bulk material, has an extremely small iron loss, as the magnetic powder filler is covered by the polymer resin. Furthermore, the shape and manufacturing method can be freely selected because it is made from polymer resin. Magnetic wedges can be manufactured by casting them into a mold or directly injecting them into a slot opening and heat curing.

However, the relative permeability of the magnetic composite material is very low compared with the corresponding value for a magnetic steel sheet.

\section{Relationship Between the Magnetic Flux Density of the Airgap and Magnetic Wedges}

To confirm the effect of the magnetic wedge, magnetic characteristics related to torque and loss are expressed using a theoretical equation.

The torque of the motor is given by ${ }^{(16)}$ 。

$$
T=\frac{\partial W_{m}^{\prime}}{\partial \theta}=\frac{p \tau l}{2 \pi} \int_{0}^{2 \pi} B_{g} F_{s} d \theta \quad(\mathrm{N} \cdot \mathrm{m}) .
$$

where $W_{\mathrm{m}}$ ' denotes magnetic coenergy $(\mathrm{J}), p$ denotes number of pole pairs, $\tau$ denotes pole pitch, $l$ denotes stack thickness $(\mathrm{m}), B_{\mathrm{g}}$ denotes magnetic flux density of airgap $(\mathrm{T}), F_{\mathrm{s}}$ denotes armature magnetomotive force (A), $\theta$ denotes rotational angle ( $\mathrm{rad} / \mathrm{s}$ ).

Assuming that the radial and circumferential components of the magnetic flux density of the gap are $B_{\mathrm{r}}$ and $B_{\theta}$, the iron loss from the sum of the eddy current loss $P_{\mathrm{e}}$ and the hysteresis loss $P_{\mathrm{h}}$ is given by ${ }^{(17)}$.

$$
\begin{aligned}
& P_{i}=P_{e}+P_{h}=\sum_{n}\left\{\int K_{e} D(n f)^{2}\left(B_{r, n}{ }^{2}+B_{\theta, n}{ }^{2}\right) d v\right. \\
& \left.+\int K_{h} D(n f)\left(B_{r, n}{ }^{2}+B_{\theta, n}{ }^{2}\right) d v\right\}
\end{aligned}
$$

where $K_{\mathrm{e}}$ denotes the coefficient of the eddy current loss of the magnetic steel sheet, $D$ denotes the density of the magnetic steel sheet $\left(\mathrm{kg} / \mathrm{m}^{3}\right), n$ denotes the harmonic order, $f$ denotes the frequency $(\mathrm{Hz}), B_{\mathrm{r}}, B_{\theta}$ denotes the flux density at the radial and circumferential axis $(\mathrm{T})$, and $K_{\mathrm{h}}$ denotes the coefficient of hysteresis loss of the magnetic steel sheet.

Equations (1) and (2) are given in the series form of the magnetic flux density harmonic component. Iron loss $P_{\mathrm{i}}$ occurs over the entire motor, but more iron loss occurs in the core near the airgap where the change in magnetic flux density is remarkable. Then, the magnetic flux density of the airgap in equations (1) and (2) is developed as a theoretical equation from the permanent magnet magnetomotive force $F_{\mathrm{mr}}$ and the gap permeance $P_{\mathrm{g}}{ }^{(16)}$.

The positional relationship between stator and rotor is given by

$$
\theta_{2}=\theta_{1}-\xi \phi_{2}-\omega_{m} t \quad(\mathrm{rad}) \text {. }
$$

where $\theta_{1}$ denotes the center axis of the u-coil, $\theta_{2}$ denotes the $\mathrm{d}$-axis of the rotor, $\xi \phi_{2}$ denotes the angle between both axes, and $\omega_{\mathrm{m}}$ denotes the angular velocity of the rotor.

The magnetomotive force of the permanent magnet $F_{\mathrm{mr}}$ is given by

$$
F_{m r}=\sum_{n} F_{m r n} \cos \left(n p \theta_{2}\right)
$$

where $n$ denotes a positive integer containing zero, $F_{\mathrm{mr}}$ denotes the amplitude of the $n^{\text {th }}$ harmonic in the magnetomotive force (A), and $p$ denotes the number of pole pairs.

Gap permeance $P_{\mathrm{g}}$ is given by

$$
P_{g}=\sum_{\alpha} \sum_{\gamma} P_{\gamma \alpha} \cos \left(\alpha N_{s} \theta_{1}+\gamma p \theta_{2}\right)
$$

where $\alpha$ and $\gamma$ denote an integer and $P_{\alpha \gamma}$ denotes the amplitude of permeance $\left(\mathrm{H}^{-1}\right)$.

Therefore, the magnetic flux density of the airgap is given by

$$
\begin{aligned}
B_{g}= & F_{m r} P_{g}=\sum_{n} \sum_{\alpha} \sum_{\gamma} F_{m r n} P_{\gamma \alpha} \cos \left\{\left\{\alpha N_{s}+(n+\gamma) p\right\} \theta_{1}\right. \\
& \left.-(n+\gamma) p \omega_{m} t-(n+\gamma) p \xi \phi_{2}\right\} \quad \text { (T) } \ldots \ldots \ldots \ldots \ldots \ldots \ldots \ldots \ldots \ldots \ldots \ldots \ldots \ldots \ldots \ldots
\end{aligned}
$$

Equation (6) is given in series form as the product of the magnetomotive force and permeance. When this harmonic component interlinks with the stator or rotor core, the magnetic flux component that does not contribute to the torque affects the harmonic iron loss. Equation (6) contains the permeance fluctuation component " $F_{\mathrm{mrn}} P_{\varepsilon \gamma} \cos \left(\varepsilon N_{\mathrm{s}} \theta_{1}\right)$ " due to the slot opening of the stator. The magnetic wedge reduces the difference in permeance between the teeth and the slot opening to suppress the harmonic components of the slot. Quantitatively grasping the change in the gap magnetic flux density is necessary. Thus, the gap magnetic flux density is calculated by FEA, and fast Fourier transform (FFT) is used to verify the suppression effect of the harmonic component.

Fig. 3 shows the points of the magnetic flux density calculated using FEA. Point A is the center point of any teeth tip in the stator, and Point $\mathrm{B}$ is the center of the airgap and moves in synchronization with the rotation of the rotor ${ }^{(18)}$.

Fig. 4 shows the magnetic flux density at the airgap and the teeth tip. Fig. 4 (a) shows the magnetic flux density waveforms at the two calculated points in Fig. 3, when the rotor is rotated $360^{\circ}$. Fig. 4 (b) shows the spectrum of the magnetic flux density at point

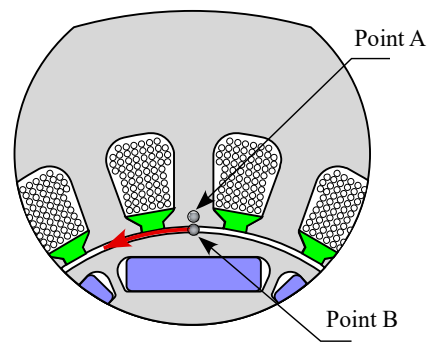

Fig. 3. Point of magnetic flux density calculated using FEA. 


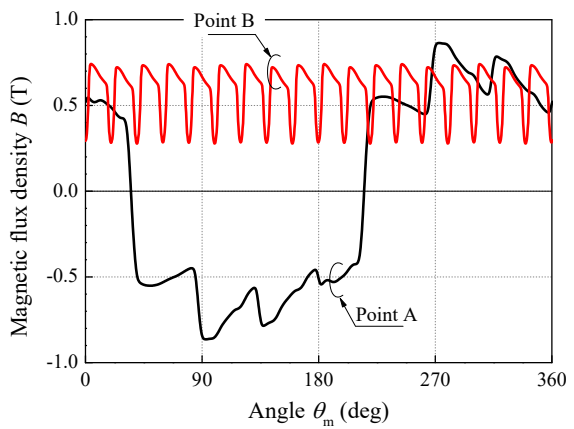

(a) Magnetic flux density vs mechanical angle $\left(w_{\mathrm{h}}=2 \mathrm{~mm}, \mu_{\mathrm{r}}=1\right)$.
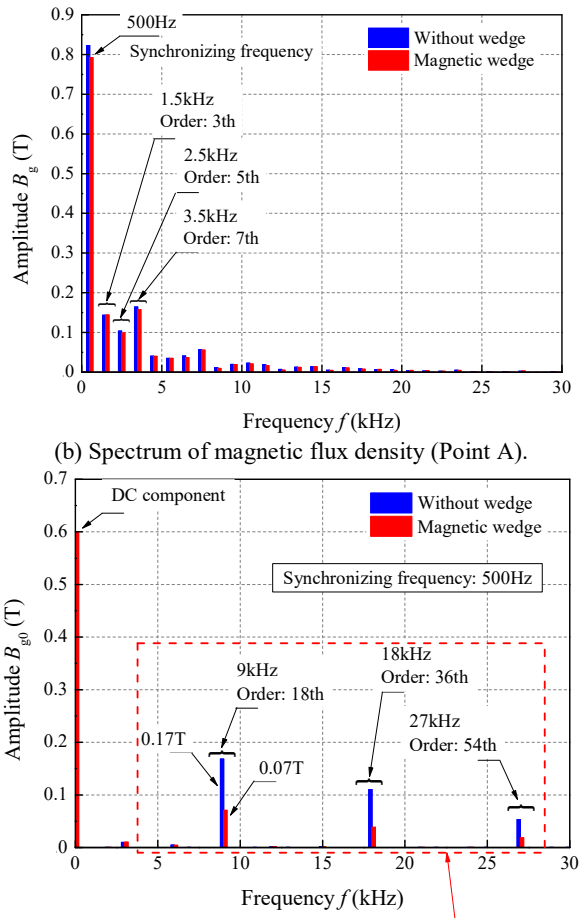

A harmonic frequency that is several times the number of slots

(c) Spectrum of magnetic flux density (Point B).

Fig. 4. Magnetic flux density at the airgap and the teeth tip $\left(30,000 \mathrm{~min}^{-1}, w_{\mathrm{h}}=2 \mathrm{~mm}, w_{\mathrm{h}} / \tau_{\mathrm{s}}=0.27, \mu_{\mathrm{r}}=5\right)$.

A. The main component of the magnetic flux density is $500 \mathrm{~Hz}$ (the synchronization frequency), and there are harmonic frequencies that are $3^{\text {rd }}, 5^{\text {th }}$, and $7^{\text {th }}$ of the synchronization frequency. These components are due to the harmonic components contained in the magnetomotive force (MMF) of the permanent magnets in the rotor ${ }^{(6)(17)(19)(20)}$. Fig. 4 (c) shows the spectrum of the magnetic flux density at point $\mathrm{B}$. The magnetic flux density is $9 \mathrm{kHz}$ (the $18^{\text {th }}$ order of the synchronization frequency), and there are harmonic frequencies 2 or 3 times that component. This result agrees with equation (6) of magnetic flux density. These components are significantly reduced using a magnetic wedge. Therefore, these results suggest that the permeance fluctuation on the stator side is suppressed.

\section{Effect of Magnetic Wedge on Torque and Loss Characteristics}

In the previous chapter, the authors showed that the magnetic wedge suppresses the fluctuation of the gap magnetic flux density due to the slot harmonics. This chapter clarifies the relationship between the torque and loss characteristics of the motor and the magnetic wedge.

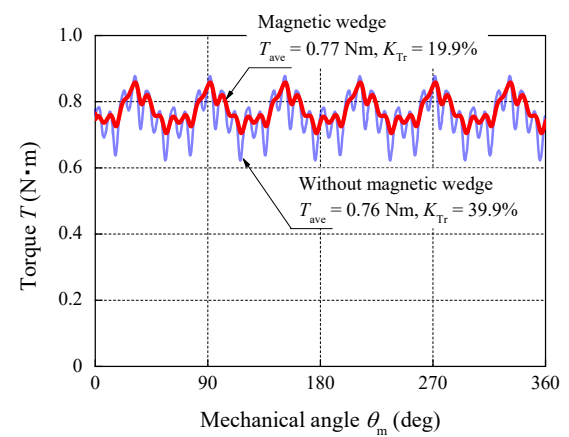

Fig. 5. Torque vs mechanical angle $\left(30,000 \mathrm{~min}^{-1}, w_{\mathrm{h}}=2 \mathrm{~mm}, w_{\mathrm{h}} / \tau_{\mathrm{s}}=0.27, \mu_{\mathrm{r}}=5\right)$

4.1 Torque Characteristics Fig. 5 shows torque as a function of the mechanical angle characteristic. Fig. 5 shows the torque waveforms when the slot opening width $w_{\mathrm{h}}=2.0 \mathrm{~mm}$ and the magnetic wedge is not used, or when the magnetic wedge with relative permeability $\mu_{\mathrm{r}}=5$ is used.

The torque ripple $K_{\operatorname{Tr}}$ is given by

$$
K_{\mathrm{Tr}}=\frac{T_{\max }-T_{\min }}{T_{\text {ave }}} \times 100 \quad(\%)
$$

where $T_{\max }$ denotes maximum torque (Nm), $T_{\min }$ denotes minimum torque $(\mathrm{Nm}), T_{\text {ave }}$ denotes average torque $(\mathrm{Nm})$.

In Fig. 5, the torque ripple is reduced by $19.9 \%$, from $39.9 \%$ to $20.0 \%$.

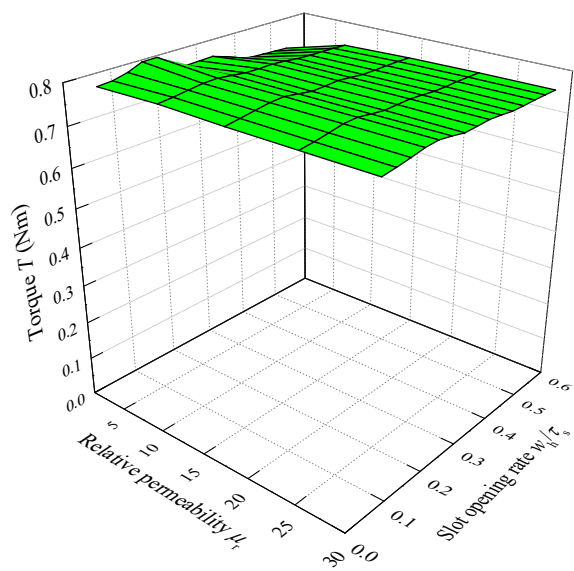

(a) Average Torque

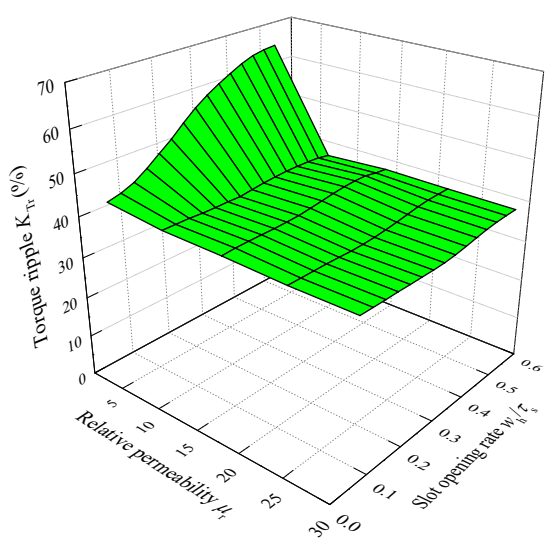

(b) Torque ripple.

Fig. 6. Torque characteristics

$\left(30,000 \mathrm{~min}^{-1}, w_{\mathrm{h}}=0.5-4.0 \mathrm{~mm}, w_{\mathrm{h}} / \tau_{\mathrm{s}}=0.07-0.55, \mu_{\mathrm{r}}=\right.$ $1-30)$. 


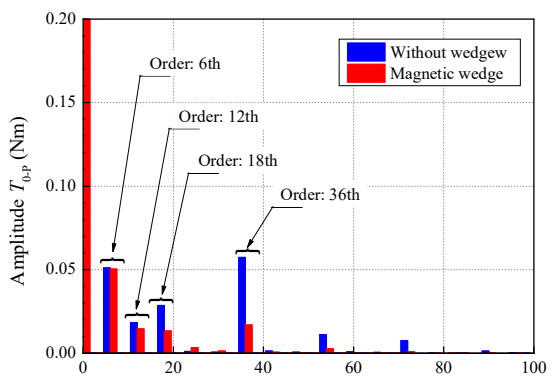

DFT Order

Fig. 7. Spectrum of torque ripple

$\left(30,000 \mathrm{~min}^{-1}, w_{\mathrm{h}}=2 \mathrm{~mm}, w_{\mathrm{h}} / \tau_{\mathrm{s}}=0.27, \mu_{\mathrm{r}}=5\right)$.

Next, the effects of magnetic wedge size and relative permeability on torque characteristics are examined. As the size of the magnetic wedge, the authors vary the slot opening width from 0.5 to $4 \mathrm{~mm}$ in 0.5 - $\mathrm{mm}$ increments. Furthermore, in this study, a slot opening rate of $w_{\mathrm{h}} / \tau_{\mathrm{s}}$ with respect to the slot pitch $\tau_{\mathrm{s}}$ is used to standardize the slot opening width. Moreover, the material characteristics of the magnetic wedge are calculated assuming the relative permeability of magnetic composite material to be virtually increased to $\mu_{\mathrm{r}}=30$.

Fig. 6 shows torque characteristics according to the magnetic wedge size and relative permeability. In Fig. 6, the average torque and torque ripple are calculated by changing the slot opening ratio $w_{\mathrm{h}} / \tau_{\mathrm{s}}$ and the relative permeability $\mu_{\mathrm{r}}$ of the magnetic wedge. The relative permeability of air is $\mu_{\mathrm{r}}=1$, and it denotes the state when no magnetic wedge is inserted. There was a concern that the magnetic wedge in the slot opening would cause a decrease in torque because of a short circuit of magnetic flux; however, as shown in Fig. 6(a), there is no drop in average torque within the range of $w_{\mathrm{h}} / \tau_{\mathrm{s}}=0.07-0.55\left(w_{\mathrm{h}}=0.5-4.0 \mathrm{~mm}\right)$ and $\mu_{\mathrm{r}}=1-30$. As shown in Fig. 6(b), torque ripple can be suppressed by the magnetic wedge. If the relative permeability of the magnetic wedge is at least $\mu_{\mathrm{r}}=10$, the torque ripple reduction is effective even if the slot opening rate increases to $w_{\mathrm{h}} / \tau_{\mathrm{s}}=0.55$ (which is about half the slot pitch). However, the suppression effect is saturated at $\mu_{\mathrm{r}}=10$. Therefore, a sufficient effect can be obtained with $\mu_{\mathrm{r}}=10$ as a magnetic composite material used for the magnetic wedge.

The torque ripple reduction mechanism is described as follows. Fig. 7 shows the spectrum of the torque waveform in Fig. 5. The $6^{\text {th }}, 12^{\text {th }}, 18^{\text {th }}$, and $36^{\text {th }}$ orders are included in the torque waveform as the main components. These harmonic components are generated by the harmonic components of the magnetic flux density contained in the airgap and can be roughly divided into three types according to the cause ${ }^{(2)}$ :

(1) The carrier harmonic components due to PWM switching superimposed on the armature current.

(2) The harmonic component of $k=6 n \pm 1$ ( $n$ : natural number) is included in the MMF of the rotor. These components are associated with the $5^{\text {th }}$ and $7^{\text {th }}$ order components in Fig. 4 (b). In addition, the $6^{\text {th }}$ harmonic component of torque appears by these harmonic components ${ }^{(21)}$.

(3) The harmonic component due to the stator slot. These components correspond to the $18^{\text {th }}$ harmonic component and its multiple-order components in Fig. 4 (c).

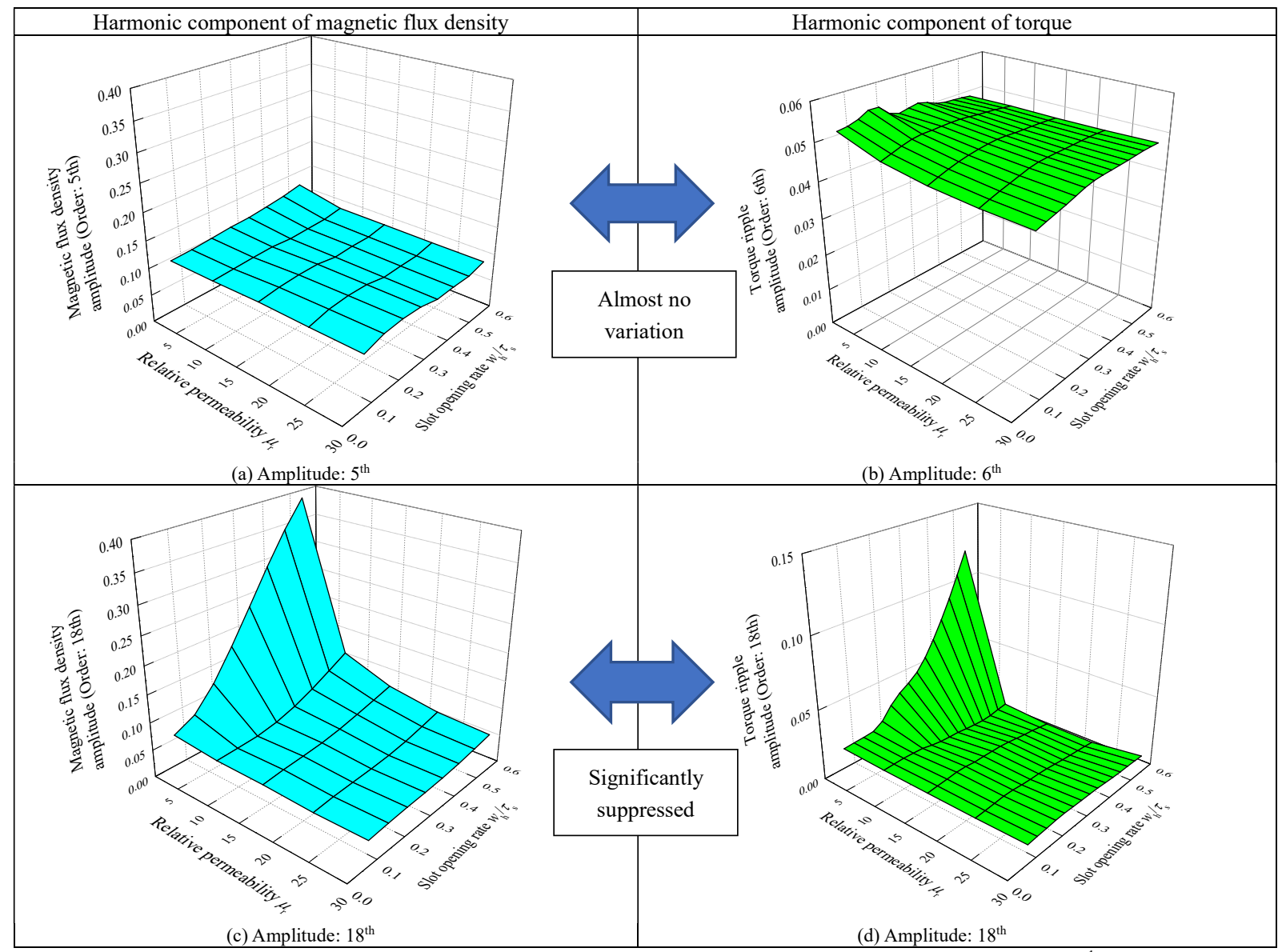

(c) Amplitude: $18^{\text {th }}$

(d) Amplitude: $18^{\text {th }}$

Fig. 8. Characteristic of magnetic flux density and torque for each frequency component $\left(30,000 \mathrm{~min}^{-1}\right)$.

$\left(30,000 \mathrm{~min}^{-1}\right.$, synchronization frequency: $\left.500 \mathrm{~Hz}, w_{\mathrm{h}}=0.5-4.0 \mathrm{~mm}, w_{\mathrm{h}} / \tau_{\mathrm{s}}=0.07-0.55, \mu_{\mathrm{r}}=1-30\right)$. 


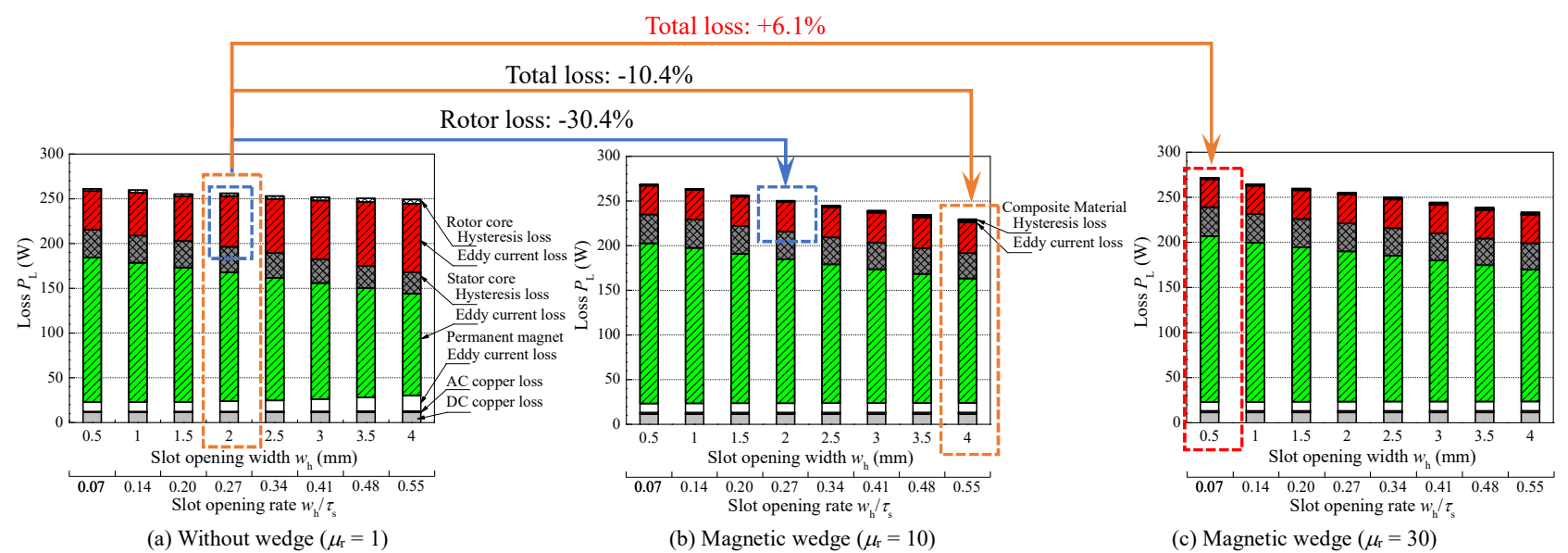

The effect of reducing torque ripple by the magnetic wedge mainly acts on the $18^{\text {th }}$ and $36^{\text {th }}$ harmonic components because the magnetic wedge suppresses the fluctuation of the harmonic component due to the stator slot.

Therefore, the correlated harmonic components are extracted in the magnetic flux density and torque. Furthermore, the effect of the magnetic wedge is verified by changing the slot opening ratio $w_{\mathrm{h}} / \tau_{\mathrm{s}}$, and relative permeability $\mu_{\mathrm{r}}$. Fig. 8 shows the characteristic of the harmonic component in the magnetic flux density and torque according to the magnetic wedge size and relative permeability. There is a correlation between the $5^{\text {th }}$ component of magnetic flux density (Fig. 8(a)) and the $6^{\text {th }}$ component of torque (Fig. 8(c)). There is almost no variation in the size and relative permeability of the magnetic wedge because the magnetic wedge is inserted in the stator slot opening, so it affects the stator side component instead of the rotor component. For the above reason, the torque ripple suppression effect is saturated even if a magnetic wedge is applied, as shown in Fig. 5 (b). On the other hand, the $18^{\text {th }}$ harmonic components of the magnetic flux density (Fig. 8(b)) and torque (Fig. 8(d)) are significantly suppressed. Thus, the magnetic wedge suppresses the permeance fluctuation by the stator slot in equation (6) and reduces the torque ripple.

4.2 Loss Characteristics Next, the effects of the magnetic wedge on loss characteristics are examined. Fig. 9 shows the loss characteristics. This figure shows the breakdown of the loss when the relative permeability is $\mu_{\mathrm{r}}=1,10$, and 30 . Same as in the previous chapter, in this study, the slot opening width was

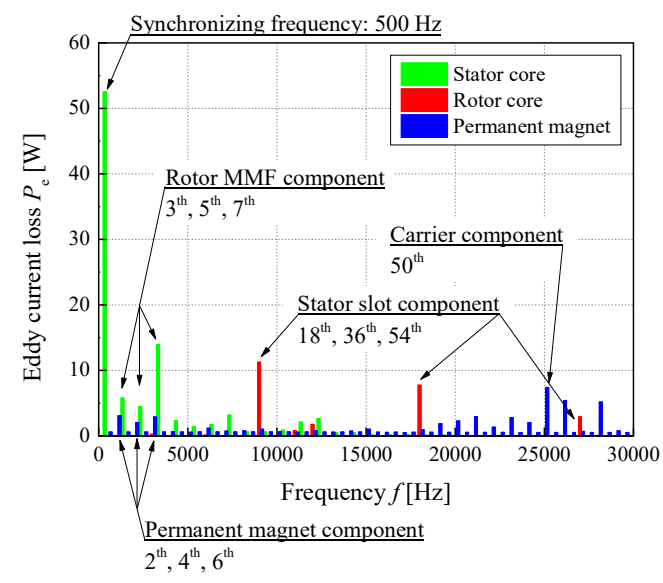

Fig. 10. Spectrum of the eddy current loss $\left(30,000 \mathrm{~min}^{-1}, w_{\mathrm{h}}=2 \mathrm{~mm}, w_{\mathrm{h}} / \tau_{\mathrm{s}}=0.27, \mu_{\mathrm{r}}=1\right)$. varied from 0.5 to $4 \mathrm{~mm}$ in $0.5-\mathrm{mm}$ increments. The main component of the loss is the eddy current loss of the stator core and rotor core. When the relative permeability was $\mu_{\mathrm{r}}=10$, the sum of the iron loss of the rotor core and the eddy current loss of the permanent magnet decreased by $30.4 \%$, from 71.2 to $49.5 \mathrm{~W}$. At $w_{\mathrm{h}} / \tau_{\mathrm{s}}=0.55$ and $\mu_{\mathrm{r}}=10$, the total loss decreased by $10.4 \%$, from 256.2 to $229.6 \mathrm{~W}$, which is the lowest total loss. However, the eddy current loss of the stator core increased when the slot opening width is reduced and the relative permeability of the magnetic wedge increased. Finally, when the relative permeability is $\mu_{\mathrm{r}}=30$, the total loss $P_{\mathrm{L}}$ increased by $6.1 \%$, from 256.2 to 271.7 $\mathrm{W}$.

To clarify the mechanism of loss reduction due to the magnetic wedge, we focus on the harmonic components of the eddy current loss, which is the primary loss in Fig. 9. Fig. 10 shows spectrum of the eddy current loss. Harmonic components of the eddy current loss are seen in three motor structures of the stator core, rotor core, and permanent magnet. The main component of the loss in the stator is the synchronization frequency $(500 \mathrm{~Hz})$, and there are harmonic frequencies that are $3^{\text {rd }}, 5^{\text {th }}$, and $7^{\text {th }}$ of the synchronization frequency. The main component of the loss in the rotor is the slot harmonic component. Moreover, the main loss component in the permanent magnet is the $6^{\text {th }}$ component, which is the same as torque ripple, and the component that is twice the carrier frequency (17) (18). Therefore, it is necessary to visualize where these harmonic iron losses occur in the motor and confirm the effect of the magnetic wedge. Therefore, this paper confirms the loss distribution for the main components of each motor structure:

(1) In the stator: Synchronous frequency $(500 \mathrm{~Hz})$.

(2) In the rotor: $18^{\text {th }}$ component $(9 \mathrm{kHz})$.

(3) In the permanent magnet: $6^{\text {th }}$ component $(3 \mathrm{kHz})$, and the component that is twice the carrier frequency $(25 \mathrm{kHz})$.

Fig. 11 shows the eddy current loss density distributions at the synchronization frequency, which is the main loss component in the stator. The eddy current loss occurred in almost all the areas of the stator, and the loss density is particularly high at the teeth tip. In addition, the loss density at the teeth tip increased if the slot opening rate decreased, and the relative permeability of the magnetic wedge increased. This is due to the increase in the leakage flux across the slot opening, so that the magnetic flux density at the teeth tip increases. Moreover, if the adjacent teeth tip distance is shortened or relative permeability of the magnetic wedge increases, the stator loss increases, as shown in Fig. 9. 


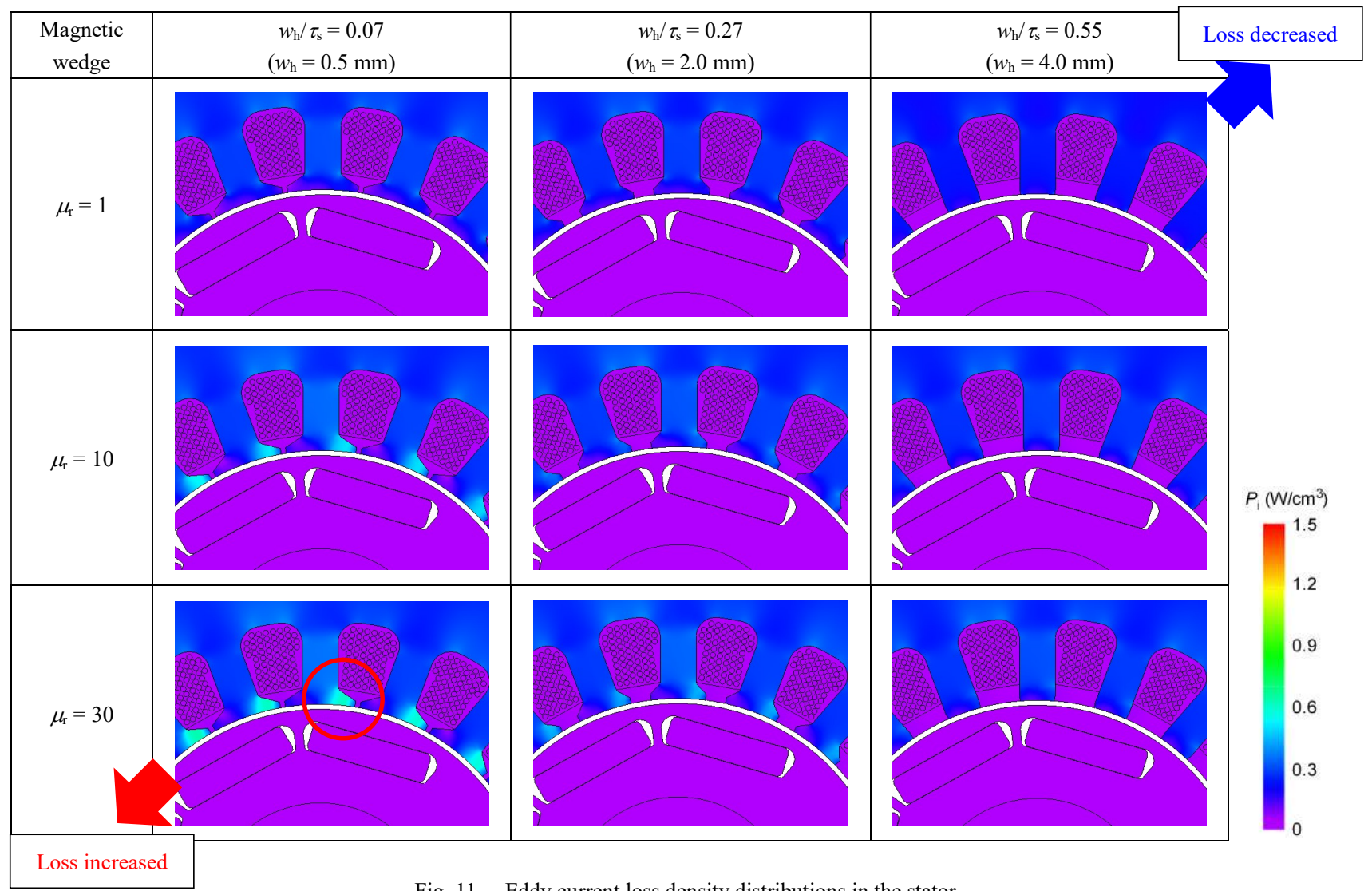

Fig. 11. Eddy current loss density distributions in the stator

$\left(500 \mathrm{~Hz}, 30,000 \mathrm{~min}^{-1}, w_{\mathrm{h}}=0.5,2.0,4.0 \mathrm{~mm}, w_{\mathrm{h}} / \tau_{\mathrm{s}}=0.07,0.27,0.55, \mu_{\mathrm{r}}=1,10\right.$, and 30$)$.

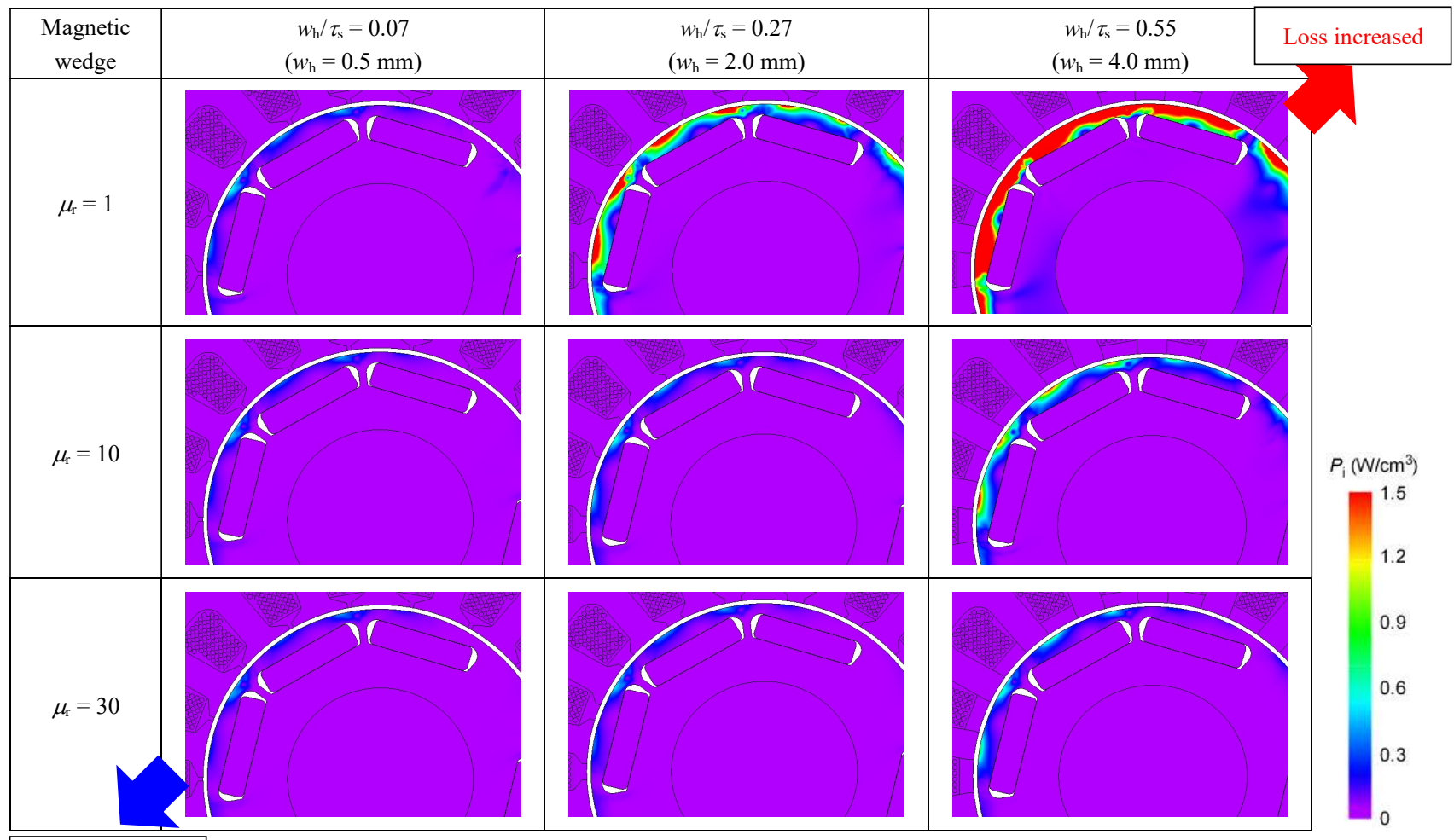

Loss decreased

Fig. 12. Eddy current loss density distributions in the rotor

$\left(9,000 \mathrm{~Hz}\right.$, synchronization frequency is $500 \mathrm{~Hz}, 30,000 \mathrm{~min}^{-1}, w_{\mathrm{h}}=0.5,2.0,4.0 \mathrm{~mm}, w_{\mathrm{h}} / \tau_{\mathrm{s}}=0.07,0.27,0.55, \mu_{\mathrm{r}}=1,10$, and 30$)$. 


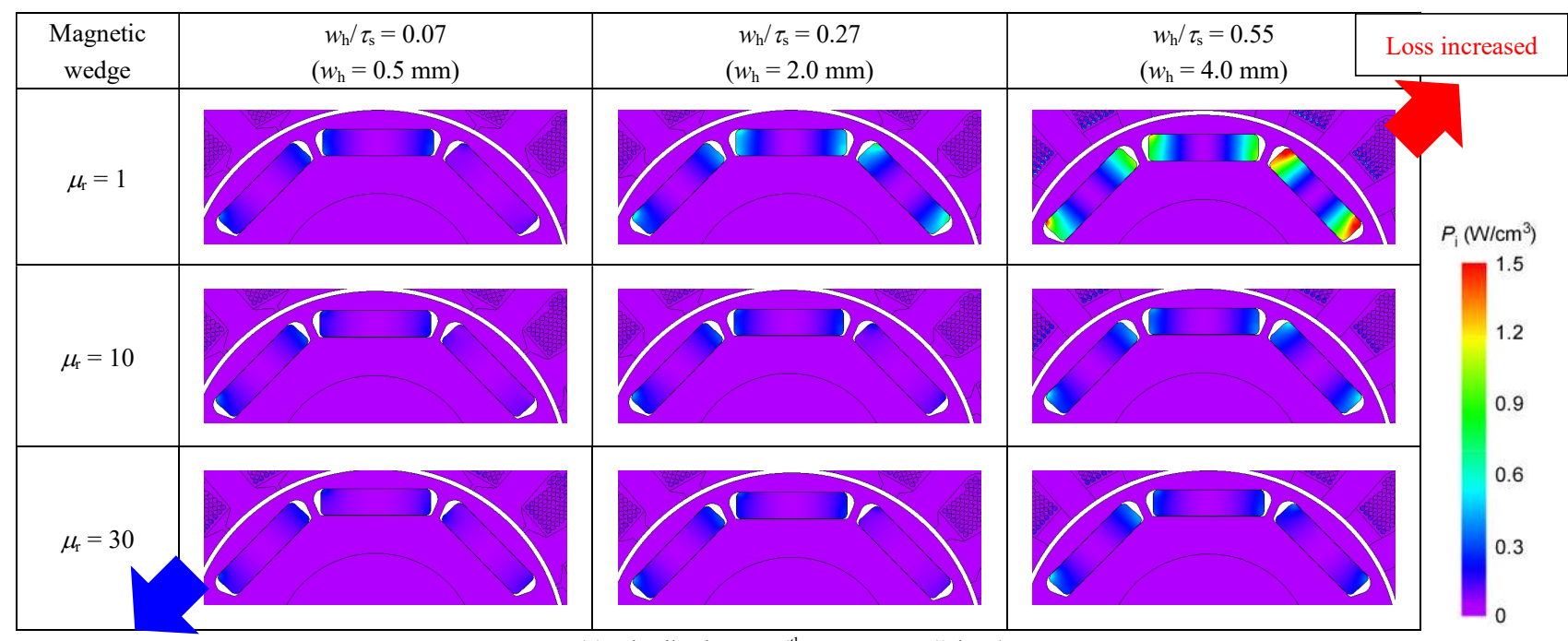

Loss decreased

(a) Distributions at $6^{\text {th }}$ component $(3 \mathrm{kHz})$.

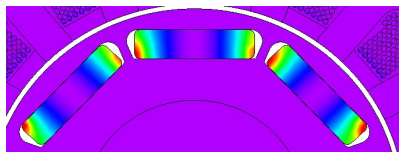

$w_{\mathrm{h}} / \tau_{\mathrm{s}}=0.55\left(w_{\mathrm{h}}=4.0 \mathrm{~mm}\right), \mu_{\mathrm{r}}=1$

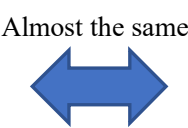

(b) Distributions at carrier harmonic frequency $(25 \mathrm{kHz})$.

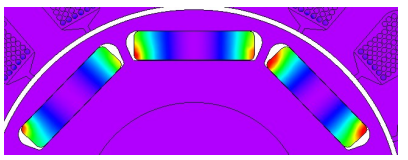

$w_{\mathrm{h}} / \tau_{\mathrm{s}}=0.07\left(w_{\mathrm{h}}=0.5 \mathrm{~mm}\right), \mu_{\mathrm{r}}=30$

Fig. 13. Eddy current loss density distributions in the permanent magnet.

(synchronization frequency is $500 \mathrm{~Hz}, 30,000 \mathrm{~min}^{-1}, w_{\mathrm{h}}=0.5,2.0,4.0 \mathrm{~mm}, w_{\mathrm{h}} / \tau_{\mathrm{s}}=0.07,0.27,0.55, \mu_{\mathrm{r}}=1,10$, and 30 ).

Fig. 12 shows the eddy current loss density distributions at the $18^{\text {th }}$ harmonic component $(9 \mathrm{kHz})$, which is the main rotor loss component. The eddy current loss of the rotor core is smaller than that of the stator core in Fig. 9. However, many losses occur locally on the surface of the rotor core, directly above the permanent magnet in particular, in Fig. 9. Therefore, there is a concern that the temperature of the permanent magnet rises. In addition, the loss density on the surface of the rotor increases if the slot opening rate increases and the relative permeability of the magnetic wedge decreases. This is the opposite tendency of stator loss because the permeance fluctuation caused by the stator slot in equation (6) increases. Thus, there is a trade-off between the iron loss at the teeth tip of the stator core and the surface of the rotor core.

Fig. 13 shows the eddy current loss density distributions at the $6^{\text {th }}$ harmonic component $(3 \mathrm{kHz})$ and the component that is twice the carrier frequency $(25 \mathrm{kHz})$, which is the main loss component in the permanent magnet. The eddy current loss occurs locally on both ends in the circumferential direction at the permanent magnet (17). In Fig. 13(a), the loss density at the $6^{\text {th }}$ harmonic component increases if the slot opening rate increases and the relative permeability of the magnetic wedge decreases. This is the same tendency as the rotor loss. Thus, the magnetic wedge is also effective in suppressing the loss of the permanent magnets. However, the loss density at the carrier harmonics in Fig. 13(b) is not affected by the slot opening rate and relative permeability of the magnetic wedge. Thus, the magnetic wedge does not affect the carrier harmonics superimposed on the current.

A design guideline is required to outline the magnetic wedge specifications because of the trade-off between the stator and rotor losses. Accordingly, Fig. 14 shows the distribution of the stator loss, rotor loss, and total loss. First, in Fig. 14 (a), the vertical lines are prominent in the distribution of the stator loss, which is strongly affected by the slot opening rate. Next, in Fig. 14 (b), the horizontal lines are prominent in distribution of the rotor loss, which is strongly affected by the relative permeability of the magnetic wedge. Thus, in Fig. 14(c), A high-efficiency design with low loss for the stator and rotor is $w_{\mathrm{h}} / \tau_{\mathrm{s}}=0.55, \mu_{\mathrm{r}}=10$. However, there is a concern that the temperature of the permanent magnets rises owing to local losses in the rotor core and

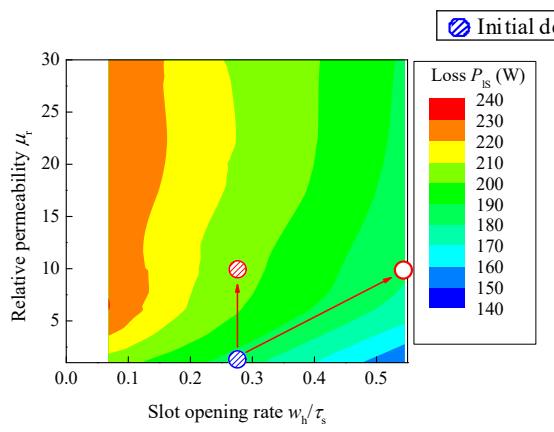

(a) Stator loss.

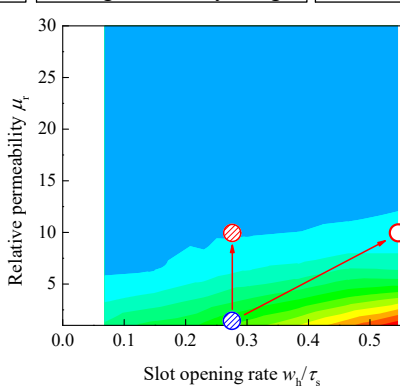

(b) Rotor loss.

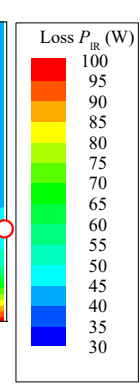

Loss $P_{\mathrm{IR}}(\mathrm{W})$
100
95
90
85
80
75
70
65
60
55
50
45
40
35
30

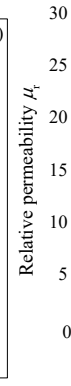

Fig. 14. Loss distribution $\left(2.16 \mathrm{~kW}, 30,000 \mathrm{~min}^{-1}, 0.686 \mathrm{Nm}, w_{\mathrm{h}}=0.5\right.$ to $4.0 \mathrm{~mm}, w_{\mathrm{h}} / \tau_{\mathrm{s}}=0.07$ to $0.55, \mu_{\mathrm{r}}=1,10$, and 30$)$. 
permanent magnets. Therefore, a design that reduces rotor loss is also important. The rotor loss decreases (Fig. 14(b)) when the relative permeability of the magnetic wedge increases. However, the improvement effect saturates when the relative permeability became larger than $\mu_{\mathrm{r}}=10$. Further, the loss of the stator increases (Fig. 14(a)) when the relative permeability became larger than $\mu_{\mathrm{r}}=$ 10. Thus, rotor loss reduction design is $w_{\mathrm{h}} / \tau_{\mathrm{s}}=0.27, \mu_{\mathrm{r}}=10$. Hence, it becomes a guideline for selecting magnetic wedge design by visualizing the change in the loss distribution. In addition, the optimum design should be determined by the total loss reduction and based on the temperature rise of the stator and rotor.

\section{Conclusions}

This paper demonstrates the mechanism of torque ripple and rotor loss reduction when magnetic wedges made from magnetic composite material are inserted into the slot opening of IPMSM. The points described in this study are summarized as follows:

(1) The magnetic wedge can suppress the slot harmonic component of the magnetic flux density. However, it has no significant effect on other components.

(2) The magnetic wedge can reduce torque ripple and rotor loss by $20.0 \%$ and $30.4 \%$, respectively. Furthermore, if the relative permeability of the magnetic wedge is at least $\mu_{\mathrm{r}}=10$, the magnetic wedge is effective even when the slot opening rate is increased to $w_{\mathrm{h}} / \tau_{\mathrm{s}}=0.55$. Therefore, even a magnetic composite material with a low relative permeability can be expected to have a sufficient improvement effect.

(3) The eddy current loss is the primary IPMSM loss when generating locally at the teeth tip of the stator, on the surface of the rotor core, and both ends in the circumferential direction at the permanent magnet. Moreover, there is a trade-off relationship between the iron losses of the stator and the rotor. Hence, the optimum design should be determined considering the total loss reduction and temperature rise of the stator and rotor.

\section{Acknowledgments}

This work was supported by JST-OPERA Program Grant Number JPMJOP1841, Japan.

\section{References}

(1) R. Mizutani, K. Haruno, and T. Mizutani: "Technical Trend of Electric Drive Assisted System for Automobile 1-Development of New Motor for Compact Class Hybrid Electric Vehicles in TOYOTA-", JIASC2017, Vol.4, No.S10-6, pp.57-62 (2017) (in Japanese)

(2) Katsumi Yamazaki, Hiroaki Ohiwa, and Kento Utsunomiya: "Studies on Rotor Shape Optimization of Interior Permanent Magnet Synchronous Motors Based on Mechanism of Torque Ripple Generation by Time and Space Harmonic Airgap Flux Densities", IEEJ Technical Meeting, MD-20-69, RM-20-44, VT-20-7, pp.19-24 (2020) (in Japanese)

(3) Hajime Hida, Yoshio Tomongashi, Kenji Ueyama, Yukinori Inoue, and Shigeo Morimoto: "New Torque Estimation Method Considering Spatial Harmonics and Torque Ripple Reduction in Permanent Magnet Synchronous Motors", IEEJ Transactions on Industry Applications, Vol.130, No.9, pp.1051-1058 (2010) (in Japanese)

(4) G. H. Lee, S. I. Kim, J. P. Hong, and J. H. Bahn, "Torque ripple reduction of interior permanent magnet synchronous motor using harmonic injected current”, IEEE Trans. Magn., vol. 44, No.6, pp.1582-1585, (2008)

(5) S. K Lee, G. H. Kang, J. Hur, and B. W. Kim, "Stator and rotor shape designs of interior permanent magnet type brushless DC motor for reducing torque fluctuation", IEEE Trans. Magn., vol.48, No.11, pp.4662-4665 (2012)

(6) Katsumi Yamazaki, Shunji Ohki, Akira Nezu, Takeshi Ikemi: "Development of Interior Permanent Magnet Motors Reducing Harmonic Iron Losses under Field Weakening Control", IEEJ Transactions on Industry Applications, Vol.127, No.8, pp.837-843 (2007) (in Japanese)

(7) Yuji Enomoto, Kenta Deguchi, and Takao Imagawa: "Development of Ultimate High-Efficiency Motor by using High-Bs Nanocrystalline Alloy", IEEJ Transactions on Industry Applications, Vol.139, No.5, pp.488-494 (2019) (in Japanese)

(8) Manabu Horiuchi, Masami Nirei, Tsutomu Mizuno, Mitsuhide Sato, Yinggang $\mathrm{Bu}$, Ryouken Masuda: "Effect of Slot Opening Width on Loss and Torque Ripple in Interior Permanent Magnet Synchronous Motor with Magnetic Wedge", IEEJ Technical Meeting, MD-20-77, RM-20-52, VT-20-15, pp.11-16 (2020)

(9) Manabu Horiuchi, Ryoken Masuda, Mitsuhide Sato, Yinggang Bu, Masami Nirei, and Tsutomu Mizuno: "Reduction of Rotor Loss and Torque Ripple in an IPMSM using Magnetic Wedges", ICEMS2020, LS3A-2, pp.498-503, (2020)

(10) Kunitoshi Kato, Hidenori Kohmo, Koichi Urabe, Takuo Takahashi: "Analytical and Experimental Study for Reducing High Frequency Pulsation Losses, Caused by the Existence of Armature Open Slots, using Magnetic Slot Wedges" IEEJ Transactions on Power and Energy, Vol. 102, No. 10, pp. 685-691 (1982) (in Japanese)

(11) Yoshihisa Anazawa, Akio Kaga, Hideo Akagami: "Characteristics and Cater's Coefficient of Small Induction Motors with Ferrite Magnetic Wedges" IEEJ Transactions on Power and Energy, Vol. 104, No. 4, pp. 246-252 (1984) (in Japanese)

(12) Shoji Isobe, Masakatsu Takemoto: "The Cater's coefficient of the iron core with magnetic wedge for rotating machinary" IEEJ Transactions on Power and Energy, Vol. 106, No. 10, pp. 844-850 (1986) (in Japanese)

(13) Koichi Matsuoka, Keiichiro Kondo Yoshitaka Kobayashi, and Shigetomo Shiraishi: "Development of Wheel Mounted Direct Drive Traction Motor for Rail Vehicle", IEEJ Transactions on Industry Applications, Vol. 121, No. 11, pp. 1176-1184 (2001) (in Japanese)

(14) Shinji Sugimoto, Akeshi Takahashi, Mikio Endo, Tatsuhiro Tamura, Hirotaka Kinoshita: "High-Efficiency Induction Motor with Small Gap Length and Magnetic Wedges" IEEJ Transactions on Industry Applications, Vol. 140, No. 4, pp. 239-245 (2020) (in Japanese)

(15) Mitsuhide Sato, Keigo Takazawa, Manabu Horiuchi, Ryoken Masuda, Ryo Yoshida, Masami Nirei, Yinggang Bu, Tsutomu Mizuno, "Reducing Rotor Temperature Rise in Concentrated Winding Motor by using Magnetic Powder Mixed Resin Ring", Energies, Vol. 13, No. 24, Art. no. 6721, pp.1-15, 2020. (IF: 2.7)

(16) Akira Ishizaki, Takeshi Tanaka, Kazuhiko Takasaki, Syoji Nishikata, Katsuyuki Watanabe, and Atsuo Katagiri: "Theory and Torque Characteristics of PM Vernier Motor" IEEJ Transactions on Industry Applications, Vol.113, No.10, pp.1192-1199 (1993) (in Japanese)

(17) Katsumi Yamazaki, Atsushi Abe: "Loss Analysis of IPM Motors Considering Carrier Harmonics", IEEJ Transactions on Industry Applications, Vol. 127, No. 1, pp. 87-94 (2007) (in Japanese)

(18) Katsumi Yamazaki: "Equivalent Circuit Parameter Caluculation of Interior Permanent Magnet Motor Involving Iron Loss Resistance Using Finite Element Method", IEEJ Transactions on Industry Applications, Vol.123, No.2, pp.67-74 (2003) (in Japanese)

(19) Bo Guan, Yifan Zhao, Yi Ruan: "Torque Ripple Minimization in Interior PM Machines using FEM and Multiple Reference Frames" Proc. of IEEE Industrial Electronics and Applications 2006 (ICIEA 2006), pp.1-6 (2006-5)

(20) Kazumasa Ide, Haruo Koharagi, Miyoshi Takahashi, Yukiyoshi Yanagisawa, Minori Nishi: "Analyzing Method of Saturatable Magnetic Flux of Rotating Machines" IEEJ Transactions on Industry Applications, Vol.114, No.4, pp. 377-386 (1994) (in Japanese)

(21) Shinji Shinnaka, Hideo Kishida: "New Simple Torque-Sensorless Torque Control for Quasi-Perfect Compensation of 6th Harmonic Torque Ripple Due to Nonsinusoidal Distribution of Back EMF of PMSM" IEEJ Transactions on Industry Applications, Vol. 131, No. 8, pp. 1068-1077 (2011) (in Japanese)

Manabu Horiuchi (Member) was born on January 12, 1982. He

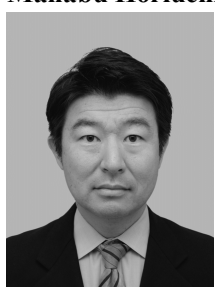
received his B.S. degrees from the Shibaura Institute of Technology, Tokyo, Japan, in 2004. He received his M.S. degrees from the Shinshu University, Nagano, Japan, in 2006. From 2006 to the present, he worked on the design and development of servo motors at Sanyo Denki Co., Ltd., Japan. He is currently pursuing his Ph.D. degree in electrical and electronic engineering at Shinshu University. His research interests include motor. He is a member of the Magnetics Society of Japan. 
Ryoken Masuda (Student Member) was born on December 22, 1997. He received his B.E. degrees from the Shinshu University, Nagano, Japan,

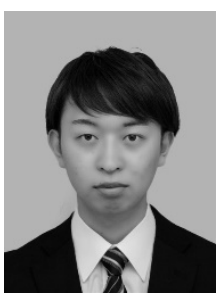

in 2020. He is currently an M.E student at the Shinshu University, Nagano. His research interests include motor.

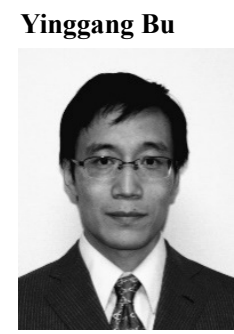

(Member) was born on October 11, 1979. He received his B.S. degree in Electrical Engineering from the Taiyuan University of Technology, China, in 2002. He received his M.S. and Ph.D. degrees in Electrical and Electronic Engineering from the Shinshu University, Japan, in 2006 and 2009, respectively. He is currently an associate professor in the Department of Engineering at the Shinshu University, Japan. His research interests include linear motors and actuators, as well as wireless power transfer. He is a member of the IEEE.

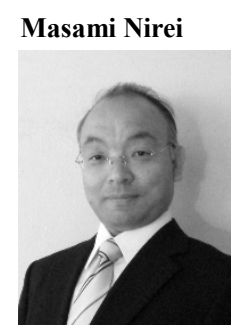

(Senior Member) is currently a professor in the Department of Electronics and Computer Science at the National Institute of Technology, Nagano College. $\mathrm{He}$ received his B.E., M.E., and D.E. degrees in electrical engineering from the Shinshu University. He worked as an engineer at the Gunma NEC from 1988 to 1990 . He joined the Shinshu University Hospital in 1990 as an assistant professor, and he was transferred to the National Institute of Technology, Nagano College, in 1991. His research work includes electromagnetic actuators and sensors, optimal design, and numerical analysis. He is a member of the IEEE, the Magnetics Society of Japan, and the Japan Society of Applied Electromagnetics and Mechanics.
Mitsuhide Sato

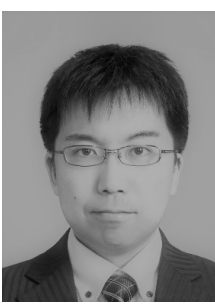

(Member) was born on May 20, 1986. He received his B.E. and M.E. degrees from the Tohoku University, Sendai, Japan, in 2009 and 2011, respectively. From 2011 to 2015, he worked as an electrical engineer at the TOSHIBA Corp., Japan. From 2015 to 2019, he had been working as a Lecturer with the Nagano Prefectural Institute of Technology, Ueda, Japan. He received his Ph.D. degree from the Shinshu University, Nagano, Japan, in 2019. He is currently an assistant professor in the Department of Engineering at the Shinshu University, Japan. His research interests include electrical equipment and power electronics. He is a member of the IEEE, and Japan Society of Applied Electromagnetics and Mechanics (JSAEM).

Tsutomu Mizuno

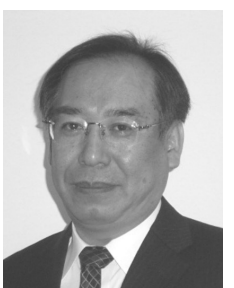

(Fellow) was born on June 17, 1958. He received his B.E. and M.E. degrees from the Shinshu University, Nagano, Japan, in 1981 and 1983, respectively. From 1983 to 1996, he worked as an electrical engineer at the AMADA CO., LTD. in Japan. From 1996 to 1999, he worked as an assistant professor; from 1999 to 2011, he worked as an associate professor. Since 2011, he has been working as a professor in the Department of Electrical and Computer Engineering, Shinshu University, Nagano, Japan. He holds a Doctor of Engineering degree from the Shinshu University. His research interests include linear motors, linear actuators, and electromagnetic sensors. He is a member of the IEEE, the Magnetics Society of Japan, and the Japan Society of Applied Electromagnetics and Mechanics (JSAEM). 